\title{
The relationship between labor pain management, cortisol level and risk of postpartum depression development: a prospective nonrandomized observational monocentric trial
}

\author{
Oksana V. Riazanova ${ }^{1}$, Yurii S. Alexandrovich ${ }^{1}$, Alexander M. Ioscovich ${ }^{2}$ \\ ${ }^{1}$ Department of Anesthesiology and Intensive Care, Saint-Petersburg State Pediatric Medical University, St. Petersburg, Russia \\ ${ }^{2}$ Department of Anesthesiology, Perioperative Medicine and Pain Treatment, Shaare Zedek Medical Center, Hebrew University, Jerusalem, \\ Israel
}

\begin{abstract}
Postpartum depression (PPD) is the main psychological status disorder and women suffering from postpartum depression often need long-term psychological and socio-economic rehabilitation. The study is dedicated to the evaluation of the role of labor pain management using epidural analgesia in natural delivery on stress level in labor and frequency of postnatal depression.

Materials and methods: 210 women were investigated and divided into two groups. In the first group for labor pain management in natural delivery, patient-controlled epidural analgesia was used (bolus - 10.0 $-0.08 \%$ ropivacaine hydrochloride, lockout $-30 \mathrm{~min}$, limit $-120 \mathrm{ml} / 6 \mathrm{~h}$ ) with a background of continuousflow infusion of local anesthetic $0.08 \%$ ropivacaine hydrocluoride solution. Patients in the second group had no pain relief in delivery. The stress level was evaluated using blood plasma cortisol level in the early stages of labor, 6 hours and 3 days after delivery. The assessment of depression development was carried out step-by-step: Before the delivery, 6 hours after, 3 days and 6 weeks after the delivery.

Results: The baby blues frequency 6 hours after the delivery in the group where the pain relief was conducted was $29.91 \%$, with cortisol level below and equal to $2310.91 \mathrm{nmol} / 1$. In the group with no pain relief 6 hours after delivery, baby blues was found in $15.53 \%$ of puerperas $(\mathrm{p}<0.05)$ and the cortisol level was $2673.82 \mathrm{nmol} / 1(\mathrm{p}<0.05)$. Six weeks after the birth, postpartum depression was diagnosed in $4.67 \%$ of women who received epidural analgesia during delivery, in comparison to $6.79 \%$ with no pain relief during delivery. However, the difference was not statistically significant $(p<0.05)$.

Conclusions: The use of epidural analgesia leads to a significant reduction of pain syndrome and stress response during natural delivery, increases the risk of baby blues in the early postnatal period, but slightly influences the frequency of postpartum depression.

Keywords: postpartum depression, baby blues, epidural analgesia, natural delivery, stress, cortisol
\end{abstract}

\section{Introduction}

Postpartum depression (PPD) is a principal psychological status disorder $[1,2]$. According to various

Address for correspondence:

Alexander M. Ioscovich

str. Hakfir 159

Jerusalem, Israel

E-mail: aioscovich@gmail.com authors, the frequency of the PPD varies from 12 to $20 \%$ puerperas, reaching $60 \%$ [3-5]. PPD occurs as a constant fatigue, sadness, psychic tension [6-8] and consequently can affect the health of women and their children in the long run [9]. Women suffering from postpartum depression often need long-term psychological and socio-economic rehabilitation $[10,11]$.

One of the risk factors in PPD development is baby blues in the early postnatal period, which manifests as 
a disorder of psycho-emotional state, and clears up without pharmacological therapy in 7-10 days after delivery [12-14].

Depression in the perinatal period can be caused by a variety of factors including past stressful life events, lack of partners support during pregnancy, obstetric complications, young age, unintended pregnancy, low socioeconomic status [15-20]. Moreover, pathophysiological mechanisms underlying depression have been discussed [19].

Much attention is given to endocrine factors associated with the pathophysiology of depression development, including the hypothalamic-pituitaryadrenal axis [21, 22]. Physiological hormone changes occur during pregnancy: the concentration of cortisol starts to increase after conception, progressively growing more than twice throughout the whole pregnancy, reaching its peak by the end of the third trimester [23-29]. This hyperactivity is partly related with the increasing level of circulating corticotrophin, that releases placental hormones $[20,30]$. After the placenta delivery, the level of cortisol is reducing, reaching the initial levels in 2 weeks after delivery [ 10 , $20,21,31-33]$. It was suggested that the disruption of the hypothalamic-pituitary-adrenal system functioning may lead to the development of depressive disorders [21, 30, 33-39].

It has been proven that increasing concentration of the stress key marker which is cortisol in the blood plasma of patients is directly related to the increasing depression rate in the overall population [40-43].

On the contrary, when examining the correlation of cortisol with the development of depressive symptomatology in obstetrics, contradictory data was obtained. Some studies have shown that increasing the level of cortisol in pregnancy results in more frequent development of PPD [20, 44-46] and the baby blues [47-51]. In other studies that association was not confirmed [21, 25, 38, 52-61]. Some authors conversely point to higher frequency of PPD at a low level of cortisol after delivery [62-64].

Recently, studies on the association between labor pain relief using epidural analgesia (EA) and the development of postpartum depression are appearing. Data from these studies show a significant decrease in the frequency of postpartum depression among women who received EA during delivery in comparison to those who had no pain relief during the delivery [65-68].

Up to the present moment, the question remains: if the blood plasma cortisol level could be related to the risk of postpartum depression among women who received epidural analgesia during delivery in comparison to puerperas with no pain relief during delivery.

\section{Materials and methods}

Following the approval of the Ethical Committee, a clinical-and-psychological examination of 210 women was conducted. All women were applied electively in the Perinatal Center of the Saint-Petersburg State Pediatric Medical University from December 2015 to March 2017, at the gestational age 34-35 weeks. Patients were offered to participate in the study. After signing informed consent to participate in the study, pregnant women completed the clinical questionnaire for neurotic states identification and evaluation [69].

To evaluate the stress level during the delivery, cortisol level in venous blood plasma during early labor stage, 6 hours after and 3 days after was measured. Taking into the consideration the physiologic diurnal cortisol level variations $[33,70]$, the first and third blood samples were collected in the morning hours (7-9 hours). Immunoenzymatic test kit (Alkor Technologies, Saint-Petersburg, Russia) was used for cortisol level evaluation. The optical density was measured using a photometer of vertical scanning Labsystems Multiskan IUS/340, Finland, wavelength $450 \mathrm{~nm}$.

During the delivery, the pain was assessed using the visual analog scale (VAS). In the postpartum period 6 hours, 3 days and 6 weeks after the delivery, the patients completed the Edinburgh Postnatal Depression Scale [71, 72]. Based on Mazo et al. (2012) study results, postpartum depression was identified with a score equal to 10 points or higher, which indicates the probability of postpartum depression [73].

All patients were divided into 2 groups, depending on the request of the women for pain relief during delivery using epidural analgesia method. In the first group, at the request of the patients, natural delivery was carried out with epidural analgesia, puncture and epidural space catheterization was conducted in the presence of regular labor activity. Patient-controlled analgesia was conducted (bolus - $10.0-0.08 \%$ of ropiacaine hydrochloride solution, lockout - $30 \mathrm{~min}$, limit $120 \mathrm{ml} / 6 \mathrm{~h}$ ) with a background continuous-flow infusion of $0.08 \%$ ropivacaine hydrochloride solution at a speed of $10 \mathrm{ml} / \mathrm{h}$. In the $2^{\text {nd }}$ group, women at the natural delivery were not receiving any analgesia as they were primed for delivery with no pain relief.

The criteria for exclusion from the study included severe somatic pathology, psychiatric disorders in the decompensation stage, purulent-septic diseases, allergy to local anesthetics, and the presence of coagulopathy or systemic treatment with anticoagulants.

The questionnaire was processed and evaluated by a psychologist who was not present at the delivery and had no information regarding the method of pain relief in delivery. 
The statistical processing of the data was carried out using the STATISTICA v. 7.0 (STATCON, Witzenhausen, Germany) software packages using non-parametric tests (Wilcoxon test), as part of the data set did not comply with the normal distribution law. The initial results of the study are presented as a median, 25 and 75 percentiles. The critical significance value is set to $\mathrm{p}<0.05$.

\section{Results}

The general characteristics of the patients surveyed are presented in Table 1. During the examination of patients, no significant difference in age and anthropometric indexes was identified in the groups studied. The age of women in first group was 29.28 (26-31) years, the age of women in second group - 30.02 (27 32) years. The body weight of women in the first group was $73.66(65.85-78.5) \mathrm{kg}$, in second group - 71.5 (6877.4). Gestational period - $39.72(39.5-40.5)$ and 39.74 (39.5-40.5) weeks respectively. However, there was no statistically significant differences between the groups $(p>0.5)$. The condition of newborn babies at birth was also not significantly different between groups, 1 min after birth the average Apgar score was $7.8(8-8), 5$ min after - $8.9(9-9)(p>0.5)$.

The results of the pain assessment during the delivery using VAS are presented in Table 2, which shows that the expression of pain syndrome during the cervical dilatation $5 \mathrm{~cm}$ and in the active pushing phase was significantly higher in patients with no pain relief, pain rates were 6.96 and 8.26 respectively in comparison to 2.5 and 4.76 in puerperas receiving EA, what was statistically significant $(p<0.05)$. On the early stage of labor (when cervical dilatation is 2-3 $\mathrm{cm}$ ), the highest ratings on the VAS scale were obtained from the patients in the first group and were 8.6 points compared to 4.7 in the second group, the difference was statistically significant $(\mathrm{p}<0.05)$.

Blood cortisol level assessment in women in the early stage, 6 hours and 3 days after delivery, is presented in Fig. 1. In the early stage of labor, prior to epidural analgezia, the cortisol level did not differ between the groups and was $2485.54 \mathrm{nmol} / 1$ and $2476.54 \mathrm{nmol} / 1$ in the first and second groups respectively $(p>0.05)$. Six hours after the delivery, cortisol level in blood plasma decreased to $2310.91 \mathrm{nmol} / 1$ in women receiving EA compared to $2673.82 \mathrm{nmol} / 1$ in patients with no pain management. Presented difference was statistically significant $(p<0.05)$. Three days after the birth, it was determined that there was no statistically significant difference of cortisol level in blood plasma of puerperas, which was 2197.46 and $2161.18 \mathrm{nmol} / 1$ in the first and second groups respectively $(\mathrm{p}>0.05)$.

The assessment of the depression of women, depending on the usage of analgezia in delivery, is

Table 1. The general characteristics of the patients

\begin{tabular}{lccc}
\hline Data & $\begin{array}{c}\text { Epidural group } \\
(\mathrm{n}=107)\end{array}$ & $\begin{array}{c}\text { Nonepidural group } \\
(\mathrm{n}=103)\end{array}$ & $\mathrm{p}$ \\
\hline Age, years & 29.28 & 30.02 & 0.081209 \\
\hline Height, $\mathrm{cm}$ & $(26-31)$ & $(27-32)$ & 0.812380 \\
\hline Weight, kg & 166.6 & 166.5 & $(163-170)$ \\
& $(163-170)$ & 71.5 & 0.422001 \\
Gestation age, weeks & 73.66 & $(68-77.4)$ & 0.130570 \\
& $(65.85-78.5)$ & 39.74 & 0.802587 \\
Apgar, 1 min & 39.72 & $(39.5-40.5)$ & 0.683091 \\
\hline Apgar, 5 min & $(39.5-40.5)$ & 7.84 & $(8-8)$ \\
\hline
\end{tabular}

Table 2. The results of the pain assessment during the delivery using VAS

\begin{tabular}{l|ccc}
\hline Data & $\begin{array}{c}\text { Epidural group } \\
(\mathrm{n}=107)\end{array}$ & $\begin{array}{c}\text { Nonepidural group } \\
(\mathrm{n}=103)\end{array}$ & $\mathrm{p}$ \\
\hline VAS, cervical dilatation $2-3 \mathrm{~cm}$ & 8.6 & 4.7 & 0.000000 \\
& $(8-10)$ & $(4-6)$ & 0.000000 \\
VAS, cervical dilatation 5 and more cm & 2.5 & 6.96 & 0.000000 \\
\hline
\end{tabular}

VAS $=$ visual analog scale 


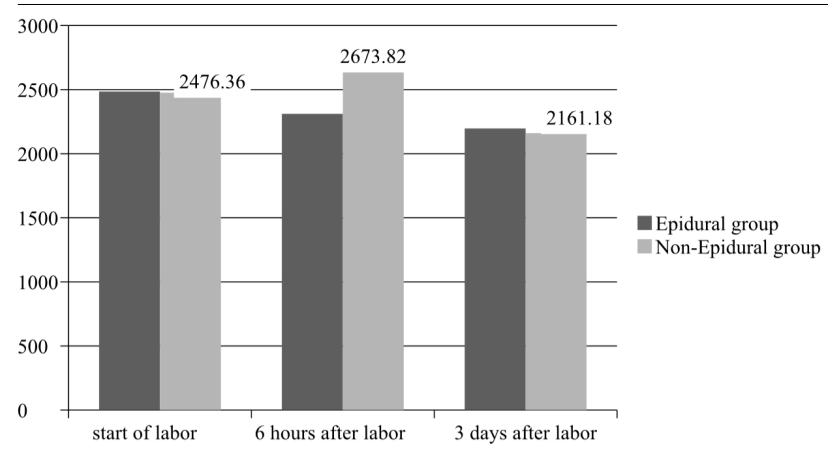

Fig. 1. Blood cortisol level assessment in women in the early stage, 6 hours and 3 days after delivery $(\mathrm{p}<0.056$ hours after labour $)$

presented in Fig. 2. The initial psychological status did not vary significantly between the groups. In the third trimester of pregnancy, depression was registered in $17.76 \%$ of women in first group and $19.42 \%$ of second relationship was not statistically relevant $(\mathrm{r}=-0.1771$, $\mathrm{p}>0.05$ ), as shown in Fig. 3.6 hours after the delivery in puerperas that received EA, the cortisol level was decreased to $2310.91 \mathrm{nmol} / 1$ compared to 2673.82 $\mathrm{nmol} / 1$ in women with no pain relief $(\mathrm{p}<0.05)$. This led to a baby blues frequency increase, which developed in $29.91 \%$ of women after analgesia, compared to $15.53 \%$ with no analgesia $(\mathrm{p}<0.05)$. However, this did not significantly affect the development of postpartum depression 6 weeks after delivery, which was registered in $4.67 \%$ of women who received pain relief in delivery compared to $6.79 \%$ with no analgesia $(\mathrm{p}>0.05)$.

\section{Discussion}

For most women, childbirth is inevitably associated with severe pain and stress, which are considered to be among the key factors of PPD development. The

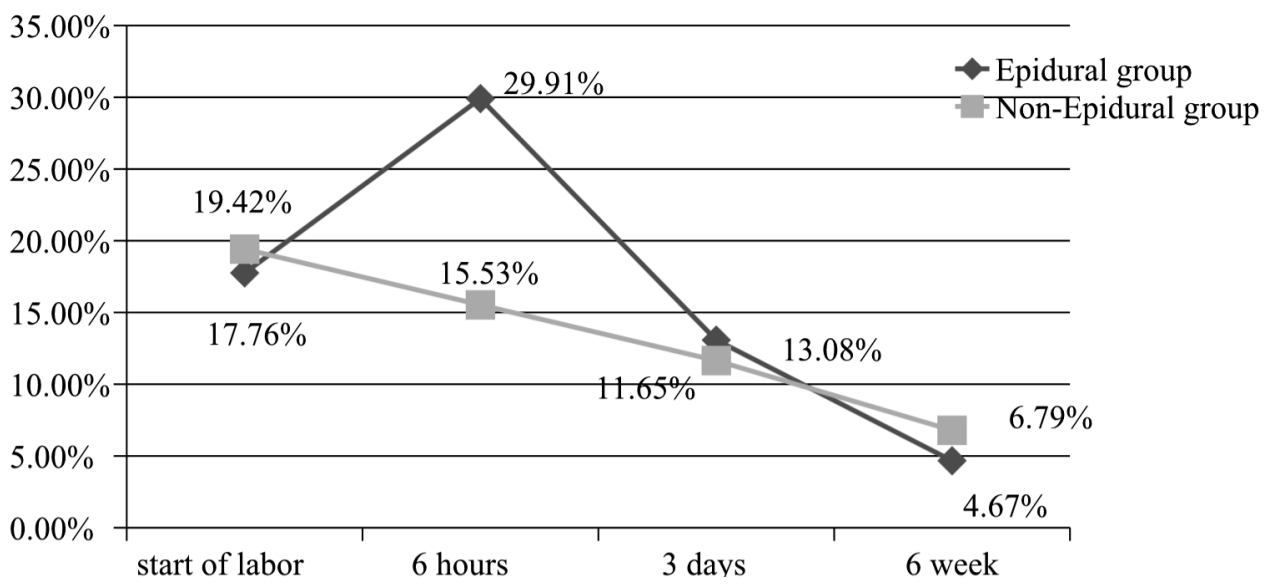

Fig. 2. The assessment of the depression of women, depending on the usage of anesthesia in delivery ( $p<0.05$ at 6 hours)

group ( $\mathrm{p}>0.05) .6$ weeks after delivery, the PPD was diagnosed in 5 out of 107 women $(4.67 \%)$ who received epidural analgesia in delivery and in 6 of 103 puerperas $(6.79 \%)$ with no pain relief during delivery, but the difference was not statistically significant ( $p>0.05)$.

Six hours after the delivery, the baby blues rate was significantly higher in puerperas, who received continued epidural analgesia in labor and was diagnosed in 32 women $(29.91 \%)$ compared to $16(15.53 \%)$ who did not receive pain relief in labor $(p<0.05)$. The cortisol level was significantly lower in the EA group compared to the group with no pain relief $(\mathrm{p}<0.05)$. For the third day after the delivery, the statistically not significant difference in the baby blues rate was $13.08 \%$ and $11.65 \%$ in the first and second groups respectively $(\mathrm{p}>0.05)$.

In the study of the cortisol level influence on the baby blues development 6 hours after the delivery, a negative correlation was detected; however, the

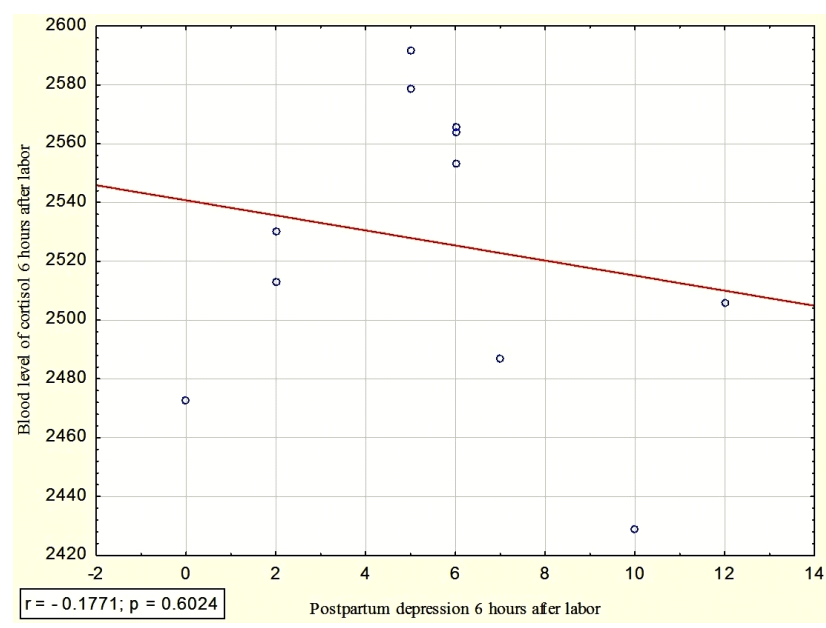

Fig. 3. The correlation between blood cortisol level and the baby blues development

overwhelming majority of puerperas described the pain suffered in childbirth as one of the worst experiences 
they had throughout their lives [33, 41, 74]. Up to $60 \%$ of primiparas describe the pain in childbirth as "severe" or "very severe" [74].

Previous studies have shown that the pain in childbirth correlates with the development of depressive disorders. Boudou et al. in 2007 and Eisenach et al., in 2013 , reported that the severity of pain in delivery was related to the risk of mood disorders during the postnatal period or depression [75, 76]. In 2008, Eisenach et al. analyzed 1228 deliveries in the United States and found that every $5^{\text {th }}$ woman after caesarean section and every $13^{\text {th }}$ woman during natural delivery suffered severe acute pain [77]. At the same time, the severity of the suffered severe pain was an independent factor for chronic pain and depression risk. The study by Soet et al. (2003) revealed a close relationship between the intensity of the pain in childbirth with posttraumatic stress and the mood disorder in the early postnatal period [78]. According to data, chronic pain syndrome after natural delivery ranges from $1 \%$ to $10 \%[76,79]$.

Our study has shown less expressed pain syndrome and stress in the case of pain relief through epidural analgesia, which is characterized by lower ratings in VAS and lower cortisol levels. But this did not have a significant impact on the risk of postpartum depression six weeks after delivery, which was recorded in $4.67 \%$ of women that received EA in comparison to $6.79 \%$ with no anesthesia $(p>0.05)$. Previous studies have shown a significant reduction of postpartum depression frequency in puerperas who received the EA during the delivery. Ding et al. (2014) reported the frequency of the PPD, 6 weeks after delivery, in $14 \%$ of women who received EA, compared to $24.3 \%$ with no analgesia [66]. Thangavelautham et al. (2016) found PPD development in $10 \%$ of puerperas who received EA, in comparison to $19.3 \%$ with no analgezia in delivery [67]. Orbach-Zinger et al., in 2017, also described the decrease of postpartum depression frequency 6 weeks after the delivery according to the Edinburgh Postnatal Depression Scale [68].

A direct correlation $[40,42,43]$ is demonstrated in studies of cortisol level effects on depressed state development in non-pregnant patients. Some authors suggested using the assay of salivary cortisol level in morning hours as a biomarker for the development of depressive episodes arising in the first year after the assessment of cortisol [80, 81, 83].

Conflicting results have been obtained in obstetrics. Stavros et al. (2015) showed a statistically higher rate of depression development in the postnatal period with higher concentrations of salivary cortisol $(\mathrm{p}=0.166, \mathrm{p}$ $<0.05$ ). In two studies it is shown that conversely, lower cortisol levels result in the depression development in the postnatal period $[22,33,34,84-86]$.
Recently, studies of depressive states development depending on the suffered stress and cortisol level have been published [29, 87, 88]. However, we did not find studies on the relationship of the pain management of delivery with the cortisol level and the frequency of the PPD. As far as we know, this study is the first one on this topic.

In our study, 6 hours after the delivery baby blues was found significantly more often $(29.91 \%)$ with a lower blood plasma cortisol level $(2310.91 \mathrm{nmol} / \mathrm{l})$ in patients of the first group, where EA was used for analgesia in labor, in comparison to $15.53 \%$ that had no analgesia, while their concentration of cortisol was significantly higher $(2673.82 \mathrm{nmol} / 1)(\mathrm{p}<0.05)$. This result can be explained by the direct influence of the epidural analgesia in childbirth on the stress reaction of the body, accompanied by a decrease blood plasma cortisol level and inversely proportional frequency of postnatal blues development 6 hours after the delivery. 3 days after the delivery, there was also a difference in the frequency of the baby blues, which was registered in $13.08 \%$ of the first group, in comparison to $11.65 \%$ of the second group, but the difference was not statistically significant $(p>0.05)$, wherein there was no difference in cortisol level in both groups. This result had a small impact on the frequency of the PPD in 6 weeks after delivery.

Our results contradict previous studies. Taylor et al. (2009) in their study showed a higher level of cortisol in women with clinical characteristics of postnatal blues and PPD [46]. Similarly, Okano et al. (1992), Lommatzsch et al. (2006) described that women with postnatal blues had a higher level of serum cortisol on the third and fourth day after delivery in comparison to healthy puerperas [44, 49]. Pedersen et al. (1993) found that women suffering from depression six weeks after delivery had significantly higher levels of serum cortisol in the morning hours [50].

On the other hand, the opposite results are shown in a number of studies. For example, Saleh et al. (2013) showed lower cortisol levels in the postnatal period for women suffering from PPD compared to healthy puerperas [64]. Groer and Morgan (2007) found a negative associative relation between the postpartum depression and the salivary cortisol level [63]. Finally, a number of studies assessing the cortisol level in relation with postpartum depression symptoms showed a minor correlation $[22,56-59,89]$. This work has one main limitation which is a lack of randomization, though it is impossible to decide whether a patient will receive epidural or not only for the sake of randomization. We plan to carry out a similar study in a number of different centers as soon as possible for additional information regarding the correlation between stress and a risk of PPD. 


\section{Conclusions}

Continuous epidural analgesia use in natural delivery has led to a reduction in the pain syndrome intensity in labor, and reduced the concentration of cortisol in the early postnatal period. However, an increase in the frequency of postpartum blues occurred on the first day after delivery. Adequate pain relief of delivery had a small impact on the postpartum depression frequency six weeks after delivery.

\section{Conflict of interest}

Nothing to declare

\section{References}

1. American Psychiatric Association. Diagnostic and statistical manual of mental disorders. $5^{\text {th }}$ ed. Arlington, VA: American Psychiatric Publishing; 2013. doi: 10.1176/appi.books. 9780890425596

2. Riazanova OV, Aleksandrovich YS, Gorkovaia IA, Korgozha MA, Koshkina YV, Ioskovich A. The impact of anesthesia during delivery on the frequency of postpartum depression of puerperas [Article in Russian]. Annals of Anesthesiology and Reanimatology 2017; 14(1): 29-35

3. Gavin NI, Gaynes BN, Lohr KN, Meltzer-Brody S, Gartlehner G, Swinson T. Perinatal depression: a systematic review of prevalence and incidence. Obstet Gynecol 2005; 106: 1071 1083. doi: 10.1097/01.AOG.0000183597.31630.db

4. Wisner KL, Moses-Kolko EL, Sit DKY. Postpartum depression: a disorder in search of a definition. Arch Womens Ment Health 2010; 13: 37-40. doi: 10.1007/s00737-009-0119-9

5. Corwin EJ, Pajer K, Paul S, Lowe N, Weber M, McCarthy DO. Bidirectional psychoneuroimmune interactions in the early postpartum period influence risk of postpartum depression. Brain Behav Immun 2015; 49: 86-93. doi: 10.1016/j.bbi.2015.04.012

6. Corwin EJ, Brownstead J, Barton N, Heckard S, Morin K. The impact of fatigue on the development of postpartum depression. J Obstet Gynecol Neonatal Nurs 2005; 34: 577-586. doi: 10.1177/0884217505279997

7. Beck CT. Postpartum depression: it isn't just the blues. Am J Nurs 2006; 106: 40-50

8. Hay DF, Pawlby S, Waters CS, Sharp D. Antepartum and postpartum exposure to maternal depression: different effects on different adolescent outcomes. J Child Psychol Psychiatry 2008; 49: 1079-1088. doi: 10.1111/j.1469-7610.2008.01959.x

9. Field T. Postpartum depression effects on early interactions, parenting, and safety practices: A review. Infant Behav Dev 2010; 33: 1-6. doi: 10.1016/j.infbeh.2009.10.005

10. Thompson KS, Fox JE. Post-partum depression: a comprehensive approach to evaluation and treatment. Ment Health Fam Med 2010; 7: 249-257

11. Markhus MW, Skotheim S, Graff IE, Frřyland L, Braarud HC, Stormark KM, et al. Low omega-3 index in pregnancy is a possible biological risk factor for postpartum depression. PLoS One 2013; 8: e67617. doi: 10.1371/journal.pone.0067617

12. Jaeschke R, Siwek M, Dudek D. Poporodowe zaburzenia nastroju - update 2012. Neuropsychiatria i Neuropsychologia. 2012; 7: $113-121$
13. O'Hara MW, McCabe JE. Postpartum depression: current status and future directions. Ann Rev Clin Psychol 2013; 9: 379-407. doi: 10.1146/annurev-clinpsy-050212-185612

14. Maliszewska K, Świątkowska-Freund M, Bidzan M, Preis K. Relationship, social support, and personality as psychosocial determinants of the risk for postpartum blues. Ginekol Pol 2016; 87: 442-447. doi: 10.5603/GP.2016.0023

15. Kumar R, Robson KM. A prospective study of emotional disorders in childbearing women. Br J Psychiatry 1984; 144: 35-47. doi: 10.1192/bjp.144.1.35

16. Brugha TS, Sharp HM, Cooper SA, Weisender C, Britto D, Shinkwin R, et al. Social support and the development of postnatal depressive symptoms, a prospective cohort survey. Psychol Med 1998; 28: 63-79

17. Milgrom J, Gemmill AW, Bilszta JL, Hayes B, Barnett B, Brooks $\mathrm{J}$, et al. Antenatal risk factors for postnatal depression: a large prospective study. J Affect Disord 2008; 108: 147-157. doi: 10.1016/j.jad.2007.10.014

18. Vesga-López O, Blanco C, Keyes K, Olfson M, Grant BF, Hasin DS. Psychiatric disorders in pregnant and postpartum women in the United States. Arch Gen Psychiatry 2008; 65: 805-815. doi: 10.1001/archpsyc.65.7.805

19. Skalkidou A, Hellgren C, Comasco E, Sylvén S, Sundstrom PI. Biological aspects of postpartum depression. Womens health (Lond) 2012; 8: 659-672. doi: 10.2217/whe.12.55

20. Iliadis SI, Comasco E, Sylvén S, Hellgren C, Sundström Poromaa I, Skalkidou A. Đrenatal and postpartum evening salivary cortisol levels in association with peripartum depressive symptoms. PLoS One 2015; 10: e0135471. doi: 10.137/journal.pone.0135471

21. Magiakou MA, Mastorakos G, Rabin D, Dubbert B, Gold PW, Chrousos GP. Hypothalamic corticotropin-releasing hormone suppression during the postpartum period: implications for the increase in psychiatric manifestations at this time. J Clin Endocrinol Metab 1996; 81: 1912-1917. doi: 10.1210/jcem. 81.5.8626857

22. Glynn LM, Davis EP, Sandman CA. New insights into the role of perinatal HPA-axis dysregulation in postpartum depression. Neuropeptides 2013; 47: 363-370. doi: 10.1016/j.npep.2013. 10.007

23. Sasaki A, Liotta AS, Luckey MM, Margioris AN, Suda T, Krieger DT. Immunoreactive corticotropin-releasing factor is present in human maternal plasma during the third trimester of pregnancy. J Clin Endocrinol Metab 1984; 59: 812-814. doi: 10.1210/jcem-59-4-812

24. Allolio B, Hoffmann J, Linton EA, Winkelmann W, Kusche M, Schulte HM. Diurnal salivary cortisol patterns during pregnancy and after delivery: relationship to plasma corticotrophinreleasing-hormone. Clinical endocrinology 1990; 33: 279-289

25. Harris B, Lovett L, Newcombe RG, Read GF, Walker R, RiadFahmy D. Maternity blues and major endocrine changes: Cardiff puerperal mood and hormone study II. BMJ 1994; 308: 949953. doi: 10.1136/bmj.308.6934.949

26. McLean M, Bisits A, Davies J, Woods R, Lowry P, Smith R. A placental clock controlling the length of human pregnancy. Nat Med 1995; 1: 460-463

27. Jung C, Ho JT, Torpy DJ, Rogers A, Doogue M, Lewis JG, et al. A longitudinal study of plasma and urinary cortisol in pregnancy and postpartum. J Clin Endocrinol Metab 2011; 96: 1533-1540. doi: $10.1210 /$ jc.2010-2395

28. Sandman C, Davis EP, Buss C, Glynn LM. Prenatal programming of human neurological function. Int J Pept 2011; 2011 : 837596. doi: $10.1155 / 2011 / 837596$ 
29. Shelton MM, Schminkey DL, Groer MW. Relationships among prenatal depression, plasma cortisol, and inflammatory cytokines. Biol Res Nurs 2015; 17: 295-302. doi: 10.1177/ 1099800414543821

30. Chrousos GP, Torpy DJ, Gold PW. Interactions between the hypothalamic-pituitary-adrenal axis and the female reproductive system: clinical implications. Ann Intern Med 1998; 129: 229240. doi: 10.7326/0003-4819-129-3-199808010-00012

31. Kalantaridou SN, Makrigiannakis A, Zoumakis E, Chrousos GP. Stress and the female reproductive system. J Reprod Immunol 2004; 62: 61-68. doi: 10.1016/j.jri.2003.09.004

32. Thompson LA, Trevathan WR. Cortisol reactivity, maternal sensitivity, and learning in 3-month-old infants. Infant Behav Dev 2008; 31: 92-106. doi: 10.1016/j.infbeh.2007.07.007

33. Seth S, Lewis AJ, Galbally M. Đerinatal maternal depression and cortisol function in pregnancy and the postpartum period: a systematic literature review. BMC Pregnancy Childbirth 2016; 16: 124. doi: 10.1186/s12884-016-0915-y

34. Hochberg Z, Pacak K, Chrousos GP. Endocrine withdrawal syndromes. Endocr Rev 2003; 24: 523-538. doi: 10.1210/ er.2001-0014

35. Halbreich U. The association between pregnancy processes, preterm delivery, low birth weight, and postpartum depressions - the need for interdisciplinary integration. Am J Obstet Gynecol 2005; 193: 1312-1322. doi: 10.1016/j.ajog.2005.02.103

36. Kammerer M, Taylor A, Glover V. The HPA axis and perinatal depression: a hypothesis. Arch Womens Ment Health 2006; 9 : 187-196. doi: 10.1007/s00737-006-0131-2

37. Vitoratos N, Papatheodorou DC, Kalantaridou SN, Mastorakos G. "Reproductive" corticotrophin-releasing hormone. Ann N Y Acad Sci 2006; 1092: 310-318. doi: 10.1196/annals.1365.029

38. Yim IS, Glynn LM, Dunkel-Schetter C, Hobel CJ, Chicz-DeMet A, Sandman CA. Risk of postpartum depressive symptoms with elevated corticotropin-releasing hormone in human pregnancy. Arch Gen Psychiatry 2009; 66: 162-169. doi: 10.1001/ archgenpsychiatry.2008.533

39. Penninx BW, Milaneschi Y, Lamers F, Vogelzangs N. Understanding the somatic consequences of depression: biological mechanisms and the role of depression symptom profile. BMC Med 2013; 11: 129. doi: 10.1186/1741-7015-11-129

40. Bhagwagar Z, Whale R, Cowen PJ. State and trait abnormalities in serotonin function in major depression. Br J Psychiatry 2002; 180: 24-28. doi: 10.1192/bjp.180.1.24

41. Lancaster CA, Gold KJ, Flynn HA, Yoo H, Marcus SM, Davis MM. Risk factors for depressive symptoms during pregnancy: a systematic review. Am J Obstet Gynecol 2010; 202: 5-14. doi: 10.1016/j.ajog.2009.09.007

42. Wei J, Sun G, Zhao L, Yang X, Liu X, Lin D, et al. Analysis of hair cortisol level in first-episodic and recurrent female patients with depression compared to healthy controls. J Affect Disord 2015; 175: 299-302. doi: 10.1016/j.jad.2015.01.023

43. Watanabe R, Kakeda S, Watanabe K, Liu X, Katsuki A, UmenoNakano W, et al. Relationship between the hippocampal shape abnormality and serum cortisol levels in first-episode and drugnad've major depressive disorder patients. Depress Anxiety 2017; 34: 401-409. doi: 10.1002/da.22604

44. Lommatzsch M, Hornych K, Zingler C, Schuff-Werner P, Höppner J, Virchow JC. Maternal serum concentrations of BDNF and depression in the perinatal period. Psychoneuroendocrinology 2006; 31: 388-394. doi: 10.1016/j.psyneuen.2005.09.003

45. Nierop A, Bratsikas A, Zimmermann R, Ehlert U. Are stressinduced cortisol changes during pregnancy associated with postpartum depressive symptoms? Psychosom Med 2006; 68: 931-937. doi: 10.1097/01.psy.0000244385.93141.3b

46. Taylor A, Glover V, Marks M, Kammerer M. Diurnal pattern of cortisol output in postnatal depression. Psychoneuroendocrinology 2009; 34: 1184-1188. doi: 10.1016/j.psyneuen.2009. 03.004

47. Handley SL, Dunn TL, Waldron G, Baker JM. Tryptophan, cortisol and puerperal mood. Br J Psychiatry 1980; 136: 498508. doi: 10.1192/bjp.136.5.498

48. Ehlert U, Patalla U, Kirschbaum C, Piedmont E, Hellhammer DH. Postpartum blues: salivary cortisol and psychological factors. J Psychosom Res 1990; 34: 319-325. doi: 10.1016/ 0022-3999(90)90088-L

49. Okano T, Nomura J. Endocrine study of the maternity blues. Prog Neuropsychopharmacol Biol Psych 1992; 16: 921-932. doi: 10.1016/0278-5846(92)90110-Z

50. Pedersen CA, Stern RA, Pate J, Senger MA, Bowes WA, Mason GA. Thyroid and adrenal measures during late pregnancy and the puerperium in women who have been major depressed or who become dysphoric postpartum. J Affect Disord 1993; 29: 201-211. doi: 10.1016/0165-0327(93)90034-H

51. Taylor A, Littlewood J, Adams D, Doré C, Glover V. Serum cortisol levels are related to moods of elation and dysphoria in new mothers. Psychiatry Res 1994; 54: 241-247. doi: 10.1016/ 0165-1781(94)90018-3

52. Harris B, Johns S, Fung H, Thomas R, Walker R, Read G, et al. The hormonal environment of postnatal depression. $\mathrm{Br} \mathrm{J}$ Psychiatry 1989; 154: 660-667. doi: 10.1192/bjp.154.5.660

53. Smith R, Cubis J, Brinsmead M, Lewin T, Singh B, Owens P, et al. Mood changes, obstetric experience and alterations in plasma cortisol, beta-endorphin and corticotrophin releasing hormone during pregnancy and the puerperium. J Psychosom Res 1990; 34: 53-69. doi: 10.1016/0022-3999(90)90008-R

54. O'Hara MW, Schlechte JA, Lewis DA, Varner MW. Controlled prospective study of postpartum mood disorders: psychological, environmental, and hormonal variables. J Abnorm Psychol 1991; 100: 63-73. doi: 10.1037/0021-843X.100.1.63

55. Susman EJ, Schmeelk KH, Worrall BK, Granger DA, Ponirakis A, Chrousos GP. Corticotropin-releasing hormone and cortisol: longitudinal associations with depression and antisocial behavior in pregnant adolescents. J Am Acad Child Adolesc Psychiatry 1999; 38: 460-467. doi: 10.1097/00004583-199904000-00020

56. Jolley SN, Elmore S, Barnard KE, Carr DB. Dysregulation of the hypothalamic-pituitary-adrenal axis in postpartum depression. Biol Res Nurs 2007; 8: 210-222. doi: 10.1177/ 1099800406294598

57. Shea AK, Streiner DL, Fleming A, Kamath MV, Broad K, Steiner M. The effect of depression, anxiety and early life trauma on the cortisol awakening response during pregnancy: preliminary results. Psychoneuroendocrinology 2007; 32: 1013-1020. doi: 10.1016/j.psyneuen.2007.07.006

58. Salacz P, Csukly G, Haller J, Valent S. Association between subjective feelings of distress, plasma cortisol, anxiety, and depression in pregnant women. Eur J Obstet Gynecol Reprod Biol 2012; 165: 225-230. doi: 10.1016/j.ejogrb.2012.08.017

59. Hellgren C, Akerud H, Skalkidou A, Sundstrom-Poromaa I. Cortisol awakening response in late pregnancy in women with previous or ongoing depression. Psychoneuroendocrinology. 2013; 38: 3150-3154. doi: 10.1016/j.psyneuen.2013.08.007

60. Meliska CJ, Martínez LF, López AM, Sorenson DL, Nowakowski $\mathrm{S}$, Kripke DF, et al. Antepartum depression severity is increased during seasonally longer nights: relationship to melatonin and 
cortisol timing and quantity. Chronobiol Int 2013; 30: 11601173. doi: $10.3109 / 07420528.2013 .808652$

61. Glynn L.M., Sandman C.A. Evaluation of the association between placental corticotrophin-releasing hormone and postpartum depressive symptoms. Psychosom Med 2014; 76 : 355-362. doi: 10.1097/PSY.0000000000000066

62. Parry BL, Sorenson DL, Meliska CJ, Basavaraj N, Zirpoli GG, Gamst A, et al. Hormonal basis of mood and postpartum disorders. Current Womens Health Rep 2003; 3: 230-235

63. Groer MW, Morgan K. Immune, health and endocrine characteristics of depressed postpartum mothers. Psychoneuroendocrinology 2007; 32: 133-139. doi: 10.1016/j.psyneuen. 2006.11.007

64. Saleh el-S, El-Bahei W, Del El-Hadidy MA, Zayed A. Predictors of postpartum depression in a sample of Egyptian women. Neuropsychiatr Dis Treat 2013; 9: 15-24. doi: 10.2147/NDT.S37156

65. Hiltunen P, Raudaskoski T, Ebeling H, Moilanen I. Does pain relief during delivery decrease the risk of postnatal depression? Acta Obstet Gynecol Scand 2004; 83: 257-261. doi: 10.1111/ j.0001-6349.2004.0302.x

66. Ding T, Wang DX, Qu Y, Chen Q, Zhu SN. Epidural labor analgesia is associated with a decreased risk of postpartum depression: a prospective cohort study. Anesth Analg 2014: 119: 383-392. doi: 10.1213/ANE.0000000000000107

67. Suhitharan T, Pham TP, Chen H, Assam PN, Sultana R, Han NL, et al. Investigating analgesic and psychological factors associated with risk of postpartum depression development: a case-control study. Neuropsychiatr Dis Treat 2016; 12: 1333-1339. doi: 10.2147/NDT.S105918

68. Orbach-Zinger S, Landau R, Harousch AB, Ovad O, Caspi L, Kornilov E, et al. The Relationship Between Women's Intention to Request a Labor Epidural Analgesia, Actually Delivering With Labor Epidural Analgesia, and Postpartum Depression at 6 Weeks: A Prospective Observational Study. Anesth. Analg 2018; 126: 1590-1597. doi: 10.1213/ANE.0000000000002501

69. Yakhin KK, Mendelevich DM. Clinical questionnaire for detection and evaluation of neurotic conditions. In: Clinical and Medical Psychology: Practical Guide: Moskva: s.n.; 1998: p. 545-552

70. Levine A, Zagoory-Sharon O, Feldman R, Lewis JG, Weller A. Measuring cortisol in human psychobiological studies. Physiol Behav 2007; 90: 43-53. doi: 10.1016/j.physbeh.2006.08.025

71. Bergant A, Nguyen T, Heim K, Ulmer H, Dapunt O. Deutschsprachige Fassung und Validierung der «Edinburgh postnatal depression scale». Dtsch Med Wochenschr 1998; 123: 35-40. doi: $10.1055 / \mathrm{s}-2007-1023895$

72. Myers ER, Aubuchon-Endsley N, Bastian LA, Gierisch JM, Kemper AR, Swamy GK, et al. Efficacy and Safety of Screening for Postpartum Depression. Comparative Effectiveness Review 106. (Prepared by the Duke Evidence-based Practice Center under Contract No. 290-2007-10066-I.) AHRQ Publication No. 13-EHC064-EF. Rockville, MD: Agency for Healthcare Research and Quality; April 2013. www.effectivehealthcare.ahrq.gov/ reports/final.cfm.

73. Mazo GE, Wasserman LI, Shamanina MV. Choosing scales for postpartum depression assessment [Article in Russian]. Review of Psychiatry and Medical Psychology 2012; 2: 41-50.

74. Melzack R, Katz J. Pain management in persons in pain. In: Wall PD, Melzack R, eds. Textbook of Pain. $4^{\text {th }}$ edition. Edinburgh: Churchill Livingstone; 1999

75. Boudou M, Teissčdre F, Walburg V, Chabrol H. Association between the intensity of childbirth pain and the intensity of postpartum blues. Encephale 2007; 33: 805-810
76. Eisenach JC, Pan P, Smiley RM, Lavand'homme P, Landau R, Houle TT. Resolution of pain after childbirth. Anesthesiology 2013; 118: 143-151. doi: 10.1097/ALN.0b013e318278ccfd

77. Eisenach JC, Pan PH, Smiley R, Lavand'homme P, Landau R, Houle TT. Severity of acute pain after childbirth, but not type of delivery, predicts persistent pain and postpartum depression. Pain 2008; 140: 87-94. doi: 10.1016/j.pain.2008.07.011

78. Soet JE, Brack GA, Dilorio C. Prevalence and predictors of women's experience of psychological trauma during childbirth. Birth 2003; 30: 36-46. doi: 10.1046/j.1523-536X.2003. 00215.x

79. Vermelis JM, Wassen MM, Fiddelers AA, Nijhuis JG, Marcus MA. Prevalence and predictors of chronic pain after labor and delivery. Curr Opin Anaesthesiol 2010; 23: 295-299. doi: 10.1097/ACO.0b013e32833853e8

80. Harris TO, Borsanyi S, Messari S, Stanford K, Cleary SE, Shiers $\mathrm{HM}$, et al. Morning cortisol as a risk factor for subsequent major depressive disorder in adult women. Br J Psychiatry 2000; 177: 505-510. doi: 10.1192/bjp.177.6.505

81. Adam EK, Doane LD, Zinbarg RE, Mineka S, Craske MG, Griffith JW. Prospective prediction of major depressive disorder from cortisol awakening responses in adolescence. Psychoneuroendocrinology 2010; 35: 921-931. doi: 10.1016/j.psyneuen. 2009

82. Goodyer IM, Croudace T, Dudbridge F, Ban M, Herbert J. Polymorphisms in BDNF (Val66Met) and 5-HTTLPR, morning cortisol and subsequent depression in at-risk adolescents. $\mathrm{Br} \mathrm{J}$ Psychiatry 2010; 197: 365-371. doi: 10.1192/bjp.bp.110. 077750

83. Vrshek-Schallhorn S, Doane LD, Mineka S, Zinbarg RE, Craske MG, Adam EK. The cortisol awakening response predicts major depression: predictive stability over a 4-year follow-up and effect of depression history. Psychol Med 2013; 43: 483-493. doi: 10.1017/S0033291712001213

84. Houshyar H, Galigniana MD, Pratt WB, Woods JH. Differential responsivity of the hypothalamic-pituitary-adrenal axis to glucocorticoid negative-feedback and corticotropin releasing hormone in rats undergoing morphine withdrawal: possible mechanisms involved in facilitated and attenuated stress responses. J Neuroendocrinol 2001; 13: 875-886. doi: 10.1046/ j.1365-2826.2001.00714.x

85. Workman JL, Barha CK, Galea LAM. Endocrine substrates of cognitive and affective changes during pregnancy and postpartum. Behav Neurosci 2012; 126: 54-72. doi: 10.1037/ a 0025538

86. Shimizu A, Nishiumi H, Okumura Y, Watanabe K. Depressive symptoms and changes in physiological and social factors 1 week to 4 months postpartum in Japan. J Affect Disord 2015; 179: 175-182. doi: 10.1016/j.jad.2015.03.036

87. Buss C, Entringer S, Reyes JF, Chicz-DeMet A, Sandman CA, Waffarn $\mathrm{F}$, et al. The maternal cortisol awakening response in human pregnancy is associated with the length of gestation. Am J Obstet Gynecol 2009; 201: 398.e1-398.e8. doi: 10.1016/ j. ajog.2009.06.063

88. Hompes T, Vrieze E, Fieuws S, Simons A, Jaspers L, Van Bussel $\mathrm{J}$, et al. The influence of maternal cortisol and emotional state during pregnancy on fetal intrauterine growth. Pediatr Res 2012; 72: 305-315. doi: 10.1038/pr.2012.70

89. Pluess M, Bolten M, Pirke KM, Hellhammer D. Maternal trait anxiety, emotional distress, and salivary cortisol in pregnancy. Biol Psychol 2010; 83: 169-175. doi: 10.1016/j.biopsycho. 2009.12.005 